Biosensors and Bioelectronics, Volume 24, Issue 5, Selected Papers from the Tenth World Congress on Biosensors Shangai, China, May 14-16, 2008, 1 January 2009, Pages 1365-1371

\title{
New Reactive Polymer for Protein Immobilisation on Sensor
}

\section{Surfaces}

Dimitris Kyprianou, Antonio R. Guerreiro, Iva Chianella *, Elena V. Piletska, Steven

A. Fowler, Kal Karim, Michael J. Whitcombe, Anthony P.F. Turner, Sergey A. Piletsky

Cranfield Health, Cranfield University, MK43 0AL, UK

*E-mail address: i.chianella.1998@cranfield.ac.uk

\begin{abstract}
Abstact
Immobilisation of biorecognition elements on transducer surfaces is a key step in the development of biosensors. The immobilisation needs to be fast, cheap and most importantly should not affect the biorecognition activity of the immobilised receptor. A novel protocol for the covalent immobilisation of biomolecules containing primary amines using an inexpensive and simple polymer is presented. This tri-dimensional (3-D) network leads to a random immobilisation of antibodies on the polymer and ensures the availability of a high percentage of antibody binding sites. The reactivity of the polymer is based on the reaction between primary amines and thioacetal groups included in the polymer network. These functional groups (thioacetal) do not need any further activation in order to react with proteins, making it attractive for sensor fabrication. The novel polymer also contains thiol derivative groups (disulphide groups or thioethers) that promote self-assembling on a metal transducer surface. For demonstration purposes the polymer was immobilised on Au Biacore chips. The
\end{abstract}


resulting polymer layer was characterised using contact angle meter, AFM and ellipsometry. A general protocol suitable for the immobilisation of bovine serum albumin (BSA), enzymes and antibodies such as polyclonal anti-microcystin-LR antibody and monoclonal anti-prostate specific antigen (anti-PSA) antibody was then optimised. The affinity characteristics of developed immunosensors were investigated in reaction with microcystin-LR, and PSA. The calculated detection limit for analytes depended on the properties of antibodies. The detection limit for microcystin-LR was $10 \mathrm{ng} \mathrm{mL} \mathrm{L}^{-1}$ and for PSA $0.01 \mathrm{ng} \mathrm{mL}^{-1}$ respectively. The non-specific binding of analytes to synthesised polymers was very low. The polymer-coated chips were stored for up to 2 months without any noticeable deterioration in their ability to react with proteins. These findings make this new polymer very promising for the development of low cost, easy to prepare and sensitive biosensors.

Keywords: SPR, thiol compounds, polymer, protein immobilisation, PSA, microcystin-LR

\section{Introduction}

The market for immunoassay and immunosensor technology in areas such as food safety, drug discovery, environment and clinical analysis is set to grow, with a steadily increasing demand for cost-effective, sensitive and easy to use sensors (Sadana, 2006). One particularly important area of biosensors is the development of point-of-care and label-free devices, with special emphasis being dedicated to clinical assays for early cancer diagnostics (Sadana, 2006; Wang, 2006). In immunosensors or enzymatic sensors, proteins are either physically adsorbed onto the sensor surface (Predki, 2004) or covalently attached via amino or thiol groups (Kusnezow and Hoheisel, 2003). Common immobilisation methods include direct covalent attachment 
of receptors/ligands onto gold surfaces or the use of an intermediate matrix, such as polymers or self-assembled monolayer, to which the biomolecules are subsequently attached. Particular care is taken to protect the immobilised receptors/ligands from denaturing processes during or post immobilisation (Butler, 2000). In some cases attempts were made to achieve oriented immobilisation, wherein the receptor is attached to a surface by a particular part of the molecule (Vikholm, 2005; Cretich et $a l ., 2006)$. It is believed that an oriented immobilisation provides superior orientation of binding sites as compared to a random immobilisation (Karyakin et al., 2000; Neubert et al., 2002; Kwon et al., 2004). Although beneficial in most cases, these processes include modification of the functional groups of the receptor molecule. Most of the techniques used are system-dependent and in some instances no actual improvement in binding performance was detected (Shriver-Lake et al., 1997; Kusnezow and Hoheisel, 2003). Other disadvantages of this oriented immobilisation include low and non-homogeneous protein deposition (Vijayendran and Leckband, 2001), reduction of binding ability of the modified antibodies (Shriver-Lake et al., 1997) and expensive, time consuming manipulations of ligands (Shriver-Lake et al., 1997; Kusnezow and Hoheisel, 2003).

Another key requirement for a sensor surface is that the matrix used for the immobilisation of the receptor should produce a low level of non-specific interactions. This is because real samples such as serum are very complex and contain thousands of different molecules (Kusnezow and Hoheisel, 2003). A low level of non-specific binding is usually achieved by inclusion of polar molecules such as polysaccharides or polyethylene glycol derivatives into the immobilisation matrix (Masson et al., 2005). Concerning antibody immobilisation, it has been demonstrated in the past that flexible porous and non-porous polymer films, consisting of various molecular weight 
polymer fractions or different length spacer arms, perform better than homogeneous flat surfaces (Masson et al., 2005). This can be attributed to an improvement of protein diffusion in the polymer matrix, together with partial protection of protein structure from unfolding processes. Rigid or solid surfaces often cause irreversible denaturation of the bound proteins (Su et al., 1998).

Here we report the synthesis of reactive polymer suitable for covalent immobilisation of proteins, or nucleic acids onto sensor surfaces. This novel polymer contains thiol derivatives (disulphide or thioethers) that promote self-assembling onto a metal transducer surface. The ligand immobilisation is based on the reaction between primary amines and thioacetale-containing polymer matrix (Simons and Johnson, 1978; Piletska et al., 2001). The product of the reaction is a fluorescence isoindole (Figure 1a and 1b). This reaction can take place without any activation, which makes this novel polymer suitable for sensor/array fabrication. In addition the flexibility of the polymeric three-dimensional (3-D) network allows a high density of receptor immobilisation, while ensuring the availability of a high percentage of its binding sites. For demonstration purposes the 3-D polymer was self-assembled onto gold Biacore chips and the entire testing was performed using the Biacore 3000 . However there is potential to use this type of material on any noble metal transducer. Initially the ability of the polymer surface to bind proteins/receptors was tested by immobilising different ligands such as bovine serum albumin (BSA), three enzymes with different isoelectric points, one type of polyclonal antibodies (anti-microcystinLR) and one type of monoclonal antibodies (anti-prostate specific antigen or antiPSA). The results obtained for the immobilisation of BSA and the three enzymes on the polymer were compared with those obtained immobilising the same proteins on commercially available pre-functionalised Biacore chips (carboxydextran CM3 and 
CM5). Finally the quality of the receptor immobilisation was evaluated by binding the antigens (microcystin-LR and PSA) to the corresponding antibodies immobilised onto the novel polymer. The encouraging results observed during this work make this new polymeric matrix very promising for the development of low cost, easy to prepare and sensitive biosensors.

\section{Materials \& Methods}

2.1. Reagents. Most compounds were obtained from commercial distributors and were of analytical or HPLC grade. Triethylamine (TEA), Bovine Serum Albumin (BSA) (lyophilized powder), anti-sheep secondary antibody (anti-sheep Ab) were purchased from Sigma (UK). Sheep polyclonal anti-microcystin-LR antibody (antimicrocystin-LR $\mathrm{Ab}$ ) was provided by Prof. Hennion from the Department of Environmental and Analytical Chemistry in Paris (Rivasseau and Hennion, 1999). Microcystin-LR was from Alexis (Switzerland). Monoclonal mouse anti-PSA antibody (anti-PSA Ab) and PSA were purchased from Serotec (UK) and Alpha Diagnostics (UK) respectively. Allyl thiol (AT), N,N'-bis(acryloyl)cystamine (BAC), o-phthaldialdehyde (OPA) were purchased from Fluka (UK). 2-hydroxyethyl methacrylate (2-HEM), ethylene glycol dimethacrylate (EGDMA), 1,1,1tris(hydroxymethyl)propan trimethacrylate (TRIM) and 2-benzyl-2(dimethylamino)4'-morpholinobutyrophenone were purchased from Aldrich (UK). Ethanolamine, 1ethyl-3-(3-dimethylaminopropyl)carbodiimide (EDC), N-hydroxysuccinimide (NHS) and sodium dodecyl sulphate (SDS) solution were purchased from Biacore (Sweden). Solvents were of analytical or HPLC grade and supplied by Acros Organics (UK).

2.2. Polymer synthesis. The polymer was synthesised by mixing together 2.0 mmol (260 mg) of 2-HEM, $0.3 \mathrm{mmol}(60 \mathrm{mg})$ of EGDMA, $1.5 \mathrm{mmol}(507 \mathrm{mg})$ of 
TRIM, $1.0 \mathrm{mmol}(134 \mathrm{mg})$ of OPA, $2.0 \mathrm{mmol}(150 \mathrm{mg})$ of AT, $0.1 \mathrm{mmol}(26 \mathrm{mg})$ BAC, $0.5 \mathrm{mmol}$ (180 mg) 2-benzyl-2(dimethylamino)-4'-morpholinobutyrophenone (initiator) and DMF (5 mL) as solvent. A small amount of TEA (40 $\mu \mathrm{L})$ was added to the monomer mixture and it was thoroughly purged with argon for 5 minutes. Polymerisation was initiated by placing the mixture under a high intensity Hönle 100 UV lamp (intensity $0.157 \mathrm{~W} \mathrm{~cm}^{-2}$ ) for 20 minutes. The synthesised polymer was precipitated from DMF by adding $20 \mathrm{~mL}$ of water and washed several times with methanol.

2.3. Evaluation of polymer activity. The assessment of the polymer reactivity was carried out by measuring fluorescence produced by the isoindole deriving from the reaction of the thioacetal group of the polymer with primary amine groups. For the experiments $20 \mathrm{mg}$ of the synthesised polymer were suspended in 3 $\mathrm{mL}$ of the following buffers: $0.1 \mathrm{M}$ sodium phosphate buffer, $\mathrm{pH} 8.0 ; 0.01 \mathrm{M}$ of phosphate buffered saline (PBS), $\mathrm{pH} 7.4 ; 0.1 \mathrm{M}$ acetate buffer, $\mathrm{pH} 5.0$ and $\mathrm{pH} 4.5$. The emission of the suspension was measured between 400 and $460 \mathrm{~nm}$ in a $3 \mathrm{~cm}^{3}$ quartz cuvette using a RF-5301 PC spectrofluorophotometer (Shidmatzu, Japan) with $370 \mathrm{~nm}$ as excitation wavelength. In order to detect the isoindole formation $5 \mu 1$ of 6 $\mathrm{M}$ ammonium hydroxide were added to the polymer suspension and the emission recorded after two minutes incubation. The fluorescence maximum was recorded at $425 \mathrm{~nm}$.

2.4. Polymer characterisation. The polymer fraction size was determined using GPC (Gel Permeation Chromatography). Polymer was dissolved in tetrahydrofuran (THF) and $20 \mu \mathrm{L}$ of $1 \mathrm{mg} \mathrm{mL}^{-1}$ solution were injected for analysis. The evaluation experiments were carried out using an Agilent 1100 SERIES HPLC system. HPLC analysis was performed at a flow-rate of $1.0 \mathrm{~mL} \mathrm{~min}{ }^{-1}$ with UV 
detection at $250 \mathrm{~nm}$. The column was Phenogel $5 \mu \mathrm{m}$ (Phenomenex $\left.{ }^{\circledR}\right)$. The column was calibrated with polystyrene standards of 13-106 $\mathrm{kDa}$ purchased from Phenomenex. The size of polymer particles expressed in polystyrene equivalents and it was calculated from the calibration curve obtained by recording the retention times.

2.5. Polymer testing. Biacore 3000 (Sweden) and Au-coated chips (SIA Kit $\mathrm{Au}$ ) purchased from Biacore (Sweden) were used in this work. All the experiments were performed at room temperature $\left(25^{\circ} \mathrm{C}\right)$.

2.6. Treatment of gold chips - gold surface modification. Sensor chips, SIA Kit $\mathrm{Au}$ (Biacore, Sweden) were used in order to assess the ability of polymer-coated surfaces to bind proteins. SIA Kit Au chips were cleaned for 3 minutes using oxygen plasma at 40 Watt in a plasma chamber (Emitech, UK). Polymer was self-assembled onto SIA Kit Au by immersing chip in $5 \mathrm{~mL}$ acetone/ethanol 50/50 v/v containing 10 $\mathrm{mg} \mathrm{mL} \mathrm{m}^{-1}$ polymer for $24 \mathrm{~h}$. The polymer-coated gold chips were rinsed thoroughly with acetone/ethanol, dried with nitrogen and assembled onto the holder.

2.7. Gold surface characterisation. The static contact angle measurements were made using a CCD camera supplied by Spectra Source Equipment model MCD400S (USA) with the software provided. The hydrophobicity was determined by measuring the interfacial tension of a drop of water on polymer coated surface.

The thickness of polymer layer was defined by ellipsometry and Atomic Force Microscopy. For the ellipsometry, the extinction coefficient of bare gold chips and the thickness values for polymer coated sensors (seven sensor chips, three measurements per chip) were obtained using a SE 400 Ellipsometer (Sentech, Germany). The roughness of the polymer layers was also measured using Atomic Force Microscopy (AFM) performed in contact mode using a PicoScan SPM from Molecular Imaging (USA). 


\subsection{Protein immobilisation on polymer-coated and carboxy-dextran}

surfaces. The protein immobilisation on sensor surfaces was monitored by Biacore 3000, which is a surface plasmon resonance (SPR) based instrument with a continuous flow system and four flow channels. The change in Biacore response units (RU) is directly proportional to the change of surface mass; one RU is approximately equivalent to 1 picogram per square millimetre. The biomolecules, which were used for studying the performance of the polymer-modified surface, were BSA, the enzymes trypsin, carbonic anhydrase and pepsin, sheep polyclonal anti-microcystin$\mathrm{LR} \mathrm{Ab}$ and mouse monoclonal anti-PSA Ab. Initially BSA was used as a model protein to assess the polymer binding capacity for biomolecules immobilisation. CM3 and CM5, which are Biacore carboxymethylated dextran chips used for biomolecule immobilisation, were tested for comparison. In this case, CM3 and CM5 were activated with EDC/NHS (Fagerstam et al., 1992) while polymer coated surface does not require any activation stage. The activation of CM3 and CM5 was performed by injecting $30 \mu \mathrm{l}$ of $0.2 \mathrm{M}$ EDC/0.05 M NHS. Typically protein immobilisation was carried out on polymer- modified surfaces by injecting $100 \mu \mathrm{L}$ of $100 \mu \mathrm{g} \mathrm{mL}^{-1}$ of protein solution in $0.01 \mathrm{M}$ phosphate buffered saline (PBS), $\mathrm{pH} 7.4$ with a flow rate $15 \mu \mathrm{L} \mathrm{min}{ }^{-1}$. Immobilisation of proteins onto CM3 and CM5 was performed in $0.1 \mathrm{M}$ Na-acetate buffer, $\mathrm{pH}$ 5.0. The stability of immobilised biomolecules on polymermodified surfaces was tested by passing $5 \mu \mathrm{L}$ of regeneration solution: $0.1 \%$, SDS (sodium dodecyl sulfate) at a flow rate of $35 \mu \mathrm{L} \mathrm{min}{ }^{-1}$.

For the immobilisation of antibodies (anti-microcystin-LR and anti-PSA Ab) $100 \mu \mathrm{L}$ (2 injections of $50 \mu \mathrm{L})$ of antibodies solution (1/1000 dilution for antimicrocystin-LR and $2 \mu \mathrm{g} \mathrm{mL}{ }^{-1}$ of anti-PSA) were injected in PBS with flow rate of 15 $\mu \mathrm{L} \mathrm{min}{ }^{-1}$. After covalent coupling of the antibodies, remaining thioacetal groups were 
deactivated by injecting $50 \mu \mathrm{L}$ of $0.2 \mathrm{M}$ ethanolamine, flow rate $10 \mu \mathrm{L} \mathrm{min}{ }^{-1}$. The assessment of the reactivity of the immobilised antibodies was carried out by injecting corresponding antigens such as microcystin-LR and PSA. The antigens were diluted in PBS buffer and injected for 3-5 minutes, with a flow rate of $10 \mu \mathrm{L} \mathrm{min}{ }^{-1}$. In all experiments a reference channel containing polymer blocked with BSA was used for assessment of binding specificity. The surface was regenerated by injecting 5-10 $\mu \mathrm{L}$ of $10 \mathrm{mM} \mathrm{HCl}$ at a flow rate of $30-35 \mu \mathrm{L} \mathrm{min}^{-1}$. The detection limit was calculated as the minimum analyte concentration which produced a signal which was at least three times the background noise.

\section{Results and Discussion}

3.1. Polymer properties. O-pthaldialdehyde and allylthiol in the presence of triethylamine react to create thioacetal groups, which can in turn react with primary amino groups with formation of a fluorescent isoindole. BAC was included in the polymer composition to supply disulphide groups useful for covalent attachment of the polymer on gold surfaces. 2-HEM increases the hydrophilicity of the polymer, usually associated with a reduction of non-specific protein adsorption. EGDMA is a bifunctional cross-linker and TRIM is a trifunctional cross-linker, which leads to a 3D polymer network and therefore to a larger surface area and higher availability of protein binding sites. In the absence of TRIM and with only EGDMA as cross-linker, the polymer capacity for proteins was up to 100 times lower, possibly due to the formation of a linear polymer, which produced a flat polymer coating too closely attached to the gold surface, so was unsuitable for sensor fabrication (results not shown). The main advantage of the 3-D polymer lies in the opportunity to avoid binding site hindrance, which could be present in high density and flat antibody layers. Together with incorrect antibody orientation, this could lead to a high 
percentage of unavailable binding sites. The tri-dimensional network leads to a random immobilisation of antibodies further away from the sensor surface, but still in close proximity to allow the detection of antigen binding (see Figure 1b).

When the reactivity of the synthesised polymer was assessed in solution at different $\mathrm{pH}$ values (by measuring the fluorescence of the formed isoindole group) a greater response was recorded in basic pHs. Nearly no fluorescence was observed for the polymer suspensions in acidic medium. The fluorescent intensity, which was recorded two minutes after addition of $\mathrm{NH}_{4} \mathrm{OH} 6 \mathrm{M}$, was $615.7 \pm 5.8 \%$ at $\mathrm{pH} 8.0$; $512.3 \pm 8.0 \%$ at $\mathrm{pH} 7.4 ; 64.4 \pm 23.7 \%$ at $\mathrm{pH} 5.0$ and $55.2 \pm 33.8 \%$ for $\mathrm{pH} 4.5$. The experiments were performed in triplicate. The fluorescence is a proof of the isoindole formation and therefore of the existence of thioacetal groups. The results also demonstrate the suitability of the polymer to perform protein immobilisation at physiological $\mathrm{pH}$, which in most cases can be advantageous to avoid protein denaturation. The average molecular weight of the polymer, as determined by GPC was $110 \mathrm{kDa}$ (polystyrene equivalent).

3.2. Characterisation of polymer-coated sensor surfaces. The polymer was attached to sensor gold surfaces by immersing the SPR chips in a polymer solution as explained in the experimental section. The study of the obtained polymer layer included contact angle measurement ellipsometry and Atomic Force Microscopy (AFM).

Contact angle measurements showed a moderately hydrophobic gold surface after modification with the polymer with an angle of $67.2^{\circ} \pm 8.9 \%$ (a very hydrophobic surface would have a value around $90^{\circ}$ ). The average thickness of the polymer chips was measured as $5.3 \pm 1.1 \% \mathrm{~nm}$ using an ellipsometer. The layer is relatively thin if compared to Biacore chips CM3 and CM5, where the carboxydextran 
layer is $30 \mathrm{~nm}$ and $100 \mathrm{~nm}$ correspondingly. Thicker layers could be obtained by leaving the chips for longer time in the polymer solution (up to one week). This resulted in increased capacity for protein, but also increased non specific binding, so a thinner layer was considered optimal for further sensor work. The small deviation in the ellipsometry value shows that the polymer coating is homogenous.

AFM measurements were carried out in contact mode for a further characterisation of the polymer layer. As it can be seen from Figure $2 \mathrm{a}$ and $2 \mathrm{~b}$ there is a change in the surface texture after the immobilisation of the polymer. A decrease in surface roughness was observed in presence of polymer (from $0.80 \mathrm{~nm}$ to $0.66 \mathrm{~nm}$ ).

3.3. SPR experiments. The evaluation of the ability of polymer to bind proteins after attachment on a sensor surface was performed using Biacore 3000. BSA was employed as a model biomolecule and a protocol for protein immobilisation on polymer was optimised. Initially the attachment of BSA to the polymer coated surface showed a satisfactory immobilisation level, which produced a Biacore signal of 1595 $\pm 3.2 \% \mathrm{RU}$ with the experiments repeated 12 times. The immobilised BSA was washed with $10 \mu \mathrm{L} 0.1 \%$ SDS solution (flow rate $35 \mu \mathrm{L} \mathrm{min}^{-1}$ ) in order to assess the affinity of immobilisation. The material was relatively stable on the surface, and less than $5 \%$ of the immobilised BSA was removed from the sensor surface by the washing step. The BSA removed during the first washing step was possibly the material which was loosely adsorbed on the surface. The remaining BSA (covalently immobilised) was completely stable and no further material losses were detected.

3.4. Effect of pH on BSA immobilisation. It is well known that protein immobilisation is highly dependent on $\mathrm{pH}$ (Branden and Tooze, 1999). In this work effect of a $\mathrm{pH}$ range of 4.5-8.0 (0.1 M acetate buffer $\mathrm{pH} 4.5,0.1 \mathrm{M}$ acetate buffer $\mathrm{pH}$ 5.0, 0.01 M PBS buffer $\mathrm{pH} 7.4$ and $0.1 \mathrm{M}$ phosphate buffer $\mathrm{pH}$ 8.0) on protein 
immobilisation was studied using BSA $\left(100 \mu \mathrm{g} \mathrm{mL}^{-1}\right)$ as a model protein. The results are illustrated in Figure 3. The experiment was carried out in triplicate. The result is consistent with the fluorescence experiments described above, where the lowest fluorescence was recorded at $\mathrm{pH} 5.0$ and 4.5. The decrement of protein binding in acidic conditions could be due to an inhibition of the isoindole formation at low $\mathrm{pH}$ and also due to variations in protein charges induced by $\mathrm{pH}$. Thus it is possible that more polar, negatively charged BSA at low $\mathrm{pH}$ will have lower affinity to relatively hydrophobic polymer surface. The highest immobilisation was achieved with PBS buffer $\mathrm{pH} 7.4$ and 8.0. We believe that $\mathrm{pH} 7.4$ would be ideal for protein immobilisation since it resembles physiological conditions.

3.5. Study of the bioreactivity of the immobilised antibodies. The maintenance of biorecognition activity of the ligands after immobilisation and minimisation of non-specific interactions between the sample and the recognition element are crucial for biosensor development. Thus, polyclonal anti-microcystin-LR $\mathrm{Ab}$ and monoclonal anti-PSA $\mathrm{Ab}$ were immobilised onto polymer-coated surfaces in order to study their ability to interact with their corresponding antigens microcystinLR and PSA.

The first set of experiments was performed with anti-microcystin-LR Ab as the immobilised ligand and microcystin-LR as binding antigen. The immobilisation of antibody for a dilution of $1 / 1000$ produced a Biacore signal of $2350 \pm 11.7 \% \mathrm{RU}$ calculated from 21 different experiments. The limit of detection for microcystin-LR was $10 \mathrm{ng} \mathrm{mL} \mathrm{m}^{-1}$. This detection limit for the toxin is relatively high in comparison to that obtained when the same antibodies were first used (Chianella et al., 2002). This can be related with the different assay format used previously (ELISA) or with the low molecular weight of microcystin $(0.995 \mathrm{kDa})$ when compared with PSA (34 kDa) 
as the signal generated on SPR systems is proportional to the mass load on the sensor surface and therefore more ideally suited for detection or large analytes.

The sensogram showing the immobilisation of anti-microcystin-LR Ab and the immunoreaction is illustrated in Figure 4. The figure also shows the regeneration step and the possibility to reuse the antibodies for further binding cycles. The amount of non-specific binding of analytes to the polymer was evaluated using a reference channel. In this channel the polymer layer was blocked with BSA (Kim et al., 2007) by injecting $100 \mu \mathrm{L}$ of $100 \mu \mathrm{gL}^{-1}$ of the protein in PBS buffer, $\mathrm{pH} 7.4$, followed by ethanolamine blocking. The binding of the highest tested concentration of microcystin-LR (100 ng mL ${ }^{-1}$ ) on this channel was negligible (lower than $20 \mathrm{RU}$ ). The low level of non-specific binding was also evidenced when, after immobilising a dilution 1/100 of anti-microcystin $\mathrm{Ab}(4618 \pm 6.8 \% \mathrm{RU})$, anti-sheep $\mathrm{Ab}$ (specific for sheep anti-microcystin-LR Ab) was injected in the system and signals of $2456 \pm$ $17.3 \% \mathrm{RU}$, and $534 \pm 12.5 \% \mathrm{RU}$ were obtained for working and reference (with polymer blocked by BSA) channels, respectively. The standard deviations were calculated for experiments performed in triplicate. These results also highlight the good availability of binding sites on the immobilised antibodies, with ca. $41 \%$ available, calculated considering that anti-microcystin-LR Ab and anti-sheep Ab have similar molecular weight.

In another set of experiments the binding of PSA to monoclonal anti-PSA Ab immobilised on polymer coated chips was studied and the calibration curve depicted on Figure 5 obtained after optimisation of the amount of antibody immobilised. The biosensor exhibited a linear detection range from $0.01 \mathrm{ng} \mathrm{mL}^{-1}$ to $1 \mathrm{ng} \mathrm{mL}^{-1}$ of PSA. This low limit of detection could be due to the usage of monoclonal antibody and the easy accessibility of the binding sites due to the structure of the polymer with 
approximately $80 \%$ binding site availability. The amount of immobilised anti-PSA was $1976 \pm 9.2 \%$ and the net PSA binding was $420.5 \pm 6.2 \%$. The higher number of available binding sites when compared with the anti-microcystin/anti-(antimicrocystin) system described above might be explained with improved accessibility/diffusion of PSA due to a lower molecular weight (34 kDa for PSA and $150 \mathrm{kDa}$ for $\mathrm{IgG})$. The detection limit achieved in our system is lower than that reported elsewhere $\left(0.027 \mathrm{ng} \mathrm{mL}^{-1}\right)$ obtained by enhanced SPR methods (Cao and Sim, 2007; Choi et al., 2008). Several concentrations of anti-PSA were tested (2.0, 1.0, $\left.0.2,0.1,0.05,0.02 \mu \mathrm{g} \mathrm{mL}^{-1}\right)$. The highest sensor responses were obtained with 2 $\mu \mathrm{g} \mathrm{mL}^{-1}(1976 \pm 9.2 \% \mathrm{RU})$, which also provided the lowest detection limit of PSA. This value was calculated for a set of 24 immobilisations and it demonstrates a good reproducibility, which could be further improved by automation of the polymer coating procedure. The storage of polymer-coated chips at room temperature and exposed to air for up to 2 months did not affect the reproducibility of these results. A longer stability study (usually 6 months) was not possible at the time.

For comparison purposes, the monoclonal anti-PSA Ab were also immobilised onto Biacore carboxymethylated dextran CM3 chip, using the immobilisation protocol suggested by the company. A very low antibody immobilisation was observed (302 RU). The quantity of the antibody immobilised on the chip surface was so low that it was difficult to detect the antigen PSA even at the highest concentrations. The calibration curve reported in Figure 5 was obtained after subtraction of the nonspecific binding, which was assessed by the amount of antigen binding to the reference channel (polymer channel blocked with BSA). The non-specific binding of PSA was increasing proportionally with PSA concentration, see Table 1. 
3.6. Influence of $\mathbf{p I}$ on protein immobilisation. A challenging aspect during the development of sensors is the immobilisation of proteins with different isoelectric points (pI). For these experiments three enzymes (pepsin, carbonic anhydrase and trypsin) with $\mathrm{pI}$ ranging form 1 to 10 were tested. The results were then compared with those obtained with the same enzymes immobilised onto commercial Biacore chips CM3 and CM5. Both CM3 and CM5 are carboxymethylated dextran chips and biomolecules can be covalently attached to their surfaces by a peptide bond formation after activation of the carboxyl groups. The main difference between the two chips is the length of the carboxydextran matrix. The thickness of the dextran layer is $100 \mathrm{~nm}$ and $30 \mathrm{~nm}$ for CM5 and CM3 respectively, whereas the thickness of our polymer layer is around $5 \mathrm{~nm}$ as measured by ellipsometry. Therefore pepsin $(\mathrm{pI}=1.0)$, carbonic anhydrase $(\mathrm{pI}=6.5)$, trypsin $(\mathrm{pI}=10)$ and $\mathrm{BSA}(\mathrm{pI}=4.5-5.5)$ were immobilised onto polymer-coated surface, CM3 and CM5. The results of the immobilisations are reported in Table 2. All the experiments were performed in triplicate.

As suggested by Biacore the immobilisation buffer used for CM3 and CM5 was $0.1 \mathrm{M}$ acetate buffer, $\mathrm{pH}$ 5.0. At this $\mathrm{pH}$ a high negatively charged carboxydextran matrix is generated. Thus this charged matrix binds preferentially to positively charged proteins (proteins with $\mathrm{pI}$ higher than 5.0). Consequently all the proteins with a pI lower than 5.0 and therefore with a negative charge would not be able to easily approach the dextran layer. In addition at $\mathrm{pH} 5.0$ some proteins might start denaturating. Hence the possibility of using a buffer with $\mathrm{pH} 7.4$, which is very close to physiological conditions, for the immobilisation of ligands onto the polymer is a significant advantage. In fact Table 2 shows that successful immobilisation of pepsin $(\mathrm{pI}=1.0)$ was achieved only on the polymer, whereas as expected practically 
no attachment was observed on CM3 and CM5, despite the significantly larger volume of CM3 and particularly CM5. As mentioned already this might have been caused by the electrostatic repulsion between the negatively charged carboxydextran matrix and the negatively charged pepsin. In contrast, the lack of a significant electrostatic charge on the polymer layer allows the negatively charged protein to approach the surface. The polymer-coated surface performed better than CM3 for most of the tested proteins with the exception of carbonic anhydrase. This might be due to the fact that this latter enzyme contains a zinc ion, which might promote electrostatic attraction to the negatively charged carboxydextran matrix.

CM5 showed in all cases, with exception of pepsin, higher binding capacity than the polymer-coated surfaces. Therefore polymer-coated surfaces are particularly advantageous when protein with low $\mathrm{pI}$ needs to be immobilised onto sensor surface. Another important advantage of the polymer-coated chip would be the cost. All the reagents involved on the synthesis of the polymer are affordable, in contrast to CM3 and CM5, which are relatively expensive.

\section{Conclusions}

The work presented here describes the development of a new low cost, fast and simple method for covalent immobilisation of proteins and other amino-containing biomolecules by employing an inexpensive and simple thioacetal-based polymer. This polymer offers a number of advantages. It contains groups that promote its selfassembling on a metal (preferable noble) transducer surface. It also contains groups that are able to bind amino-containing substances without any additional activation. Other desirable properties of the polymer are placement of appropriate amount of ligands and easy accessibility of binding sites given by the tri-dimensional polymer 
structure. Immunosensors developed on polymer coated surface showed high sensitivity for the target analyte. In fact detection limits of $10 \mathrm{ng} \mathrm{mL}^{-1}$ and $0.01 \mathrm{ng}$ $\mathrm{mL}^{-1}$ were obtained for microcystin-LR and PSA respectively. Polymer-coated surfaces possess higher loading capacity for proteins with low pI when compared with commercial Biacore chips CM3 and CM5. All these advantages in combination with low non specific binding, simple and inexpensive synthesis make this new polymer very promising for the development of low cost, easy to prepare and sensitive biosensors.

\section{Acknowledgements.}

We gratefully acknowledge the European Union, The Sixth Framework Programme (FP6-016467) for the financial support and Mrs Yildiz Uludag for the ellipsometry measurements. 


\section{References}

Branden, C., Tooze, J., 1999. Introduction to Protein Structure, $2^{\text {nd }}$ Edition, Garland Puplishing, New York, 90-91.

Butler, E. J., 2000. Methods 22 (1), 4-23.

Cao, C., Sim, S.J., 2007. Journal of Microbiology and Biotechnology 17 (6), 10311035.

Chianella, I., Lortiezo, M., Piletsky, S., Tothill, I. E., Chen, B., Karim, K., Turner, A.P.F., 2002. Analytical Chemistry 74 (6), 1288-1293.

Choi, J.W., Kang, D.,Y., Jang, Y.H., Kim, H.H., Min, J., Oh, B.K., 2008. Colloids and Surfaces A 313-314, 655-659.

Cretich, M., Damin, F., Pirri, G., Chiari, M., 2006. Biomolecular Engineering 23 (23), 77-88.

Fagerstam, L. G., Frostell, Karlsson, A., Karlsson, R., Persson, B., Ronnberg , I., 1992. Journal of Chromatography 597 (1-2), 397-410.

Karyakin, A.A., Presnova, G.V., Rubtsova, M.Y., Egorov, A.M., 2000. analytical Chemistry 72 (16), $3805-3811$.

Kim, S. J., Gobi, K. V., Iwasaka, H., Tanaka, H., Miura, N. 2007. Biosensors and Bioelectronics 23 (5), 701-707.

Kusnezow, W., Hoheisel, J.D., 2003. Journal of Molecular Recognition 16 (4), 165176.

Kwon, Y., Han, Z., Karatan, E., Mrksich, M., Kay, B.K., 2004. Analytical Chemistry $76(19), 5713-5720$.

Masson, J. F., Battaglia, M.T., Davidson, J.M., Yoon, Chang, K., Prakash, A.M.C., Beaudoin, S., Booksh, K. S., 2005. Talanta 67 (5), 918-925. 
Neubert, H., Jacoby, E.S., Bansal, S.S., Iles, R.K., Cowan, D.A., Kicman, A.T., 2002. Analytical Chemistry 74 (15), $3677-3683$.

Piletska, E.V., Piletsky, S. A., Subrahmanyam, S., Karim, K., Turner, A.P.F., 2001. Polymer 42 (8), $3603-3608$.

Predki, F. P., 2004. Current Opinion in Chemical Biology 8 (1), 8-13.

Rivasseau, C., Hennion, M.C., 1999. Analytica Chimica Acta 399 (1-2), 75-87.

Sadana, A., 2006. Market Size and Economics for Biosensors. Binding and Dissociation Kinetics for Different Biosensor Applications Using Fractals, Elsevier Science, Amsterdam, 319-342.

Shriver,Lake, L.C., Donner, B., Edelstein, R., Breslin, K., Bhatia, S.K., Ligler, F.S., 1997. Biosensors and Bioelectronics 12 (11), 1101-1106.

Simons, S., Johnson, D., 1978. Journal of Organic Chemistry 43 (14), 2286-2891.

Su, T.J., Lu, J.R., Thomas, R.K., Cui, Z.F., Penfold, J., 1998. Langmuir 14 (2), 438 445.

Vijayendran, R.A., Leckband, D.E., 2001. Analytical Chemistry 73 (3), 471-480.

Vikholm, I., 2005. Sensors and Actuators B 106 (1), 311-316.

Wang, J., 2006. Biosensors and Bioelectronics 21 (10), 1887-1892. 


\section{Figure Captions}

(a)
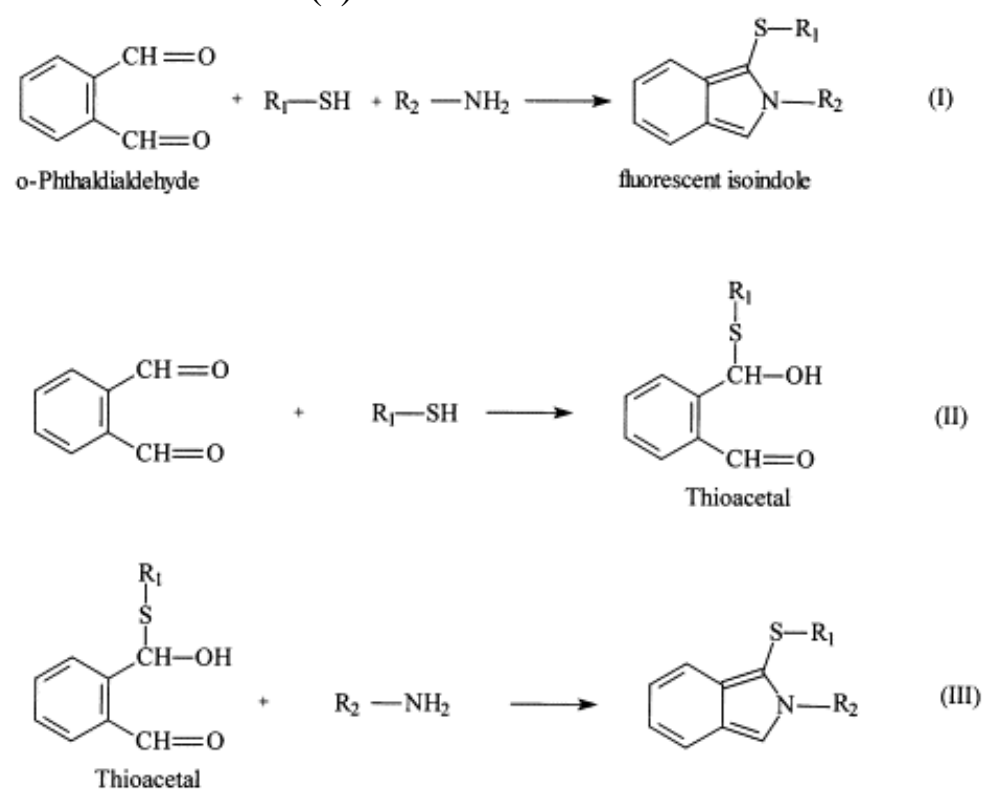

(b)

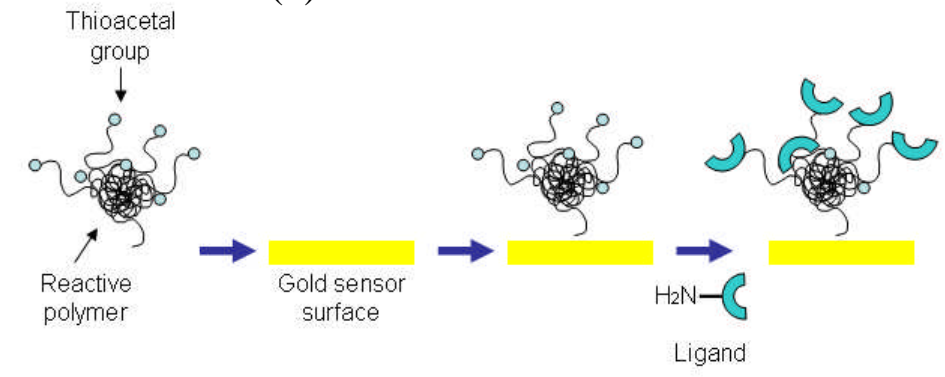

Figure 1. (a) The reaction between o-phthaldialdehyde, mercaptan and primary amine (I), hemithioacetal formation (II), formation of the fluorescent isoindole complex between hemithioacetal and primary amine (III). $\mathrm{R}_{1}-\mathrm{SH}$ is a polymerisable mercaptan, which will be included in the polymer, $\mathrm{R}_{2}-\mathrm{NH}_{2}$ represents any primary amine. (b) Schematic representation of biomolecule immobilisation on the tridimensional polymer-coated gold surface. 
(a)

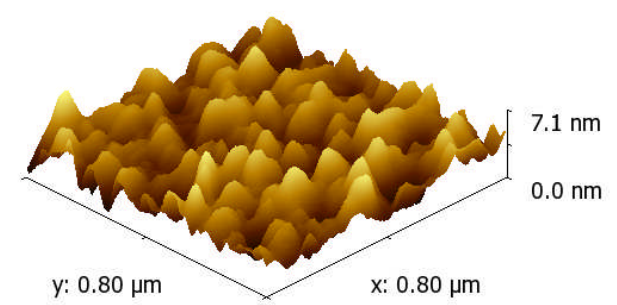

(b)

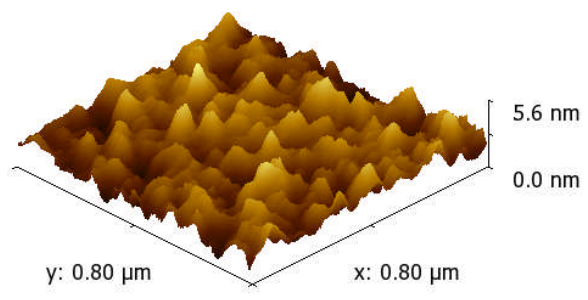

Figure 2. AFM topographies of (a) cleaned gold substrate and (b) polymer-coated surface with respective roughness of $0.8 \mathrm{~nm}$ and $0.66 \mathrm{~nm}$.

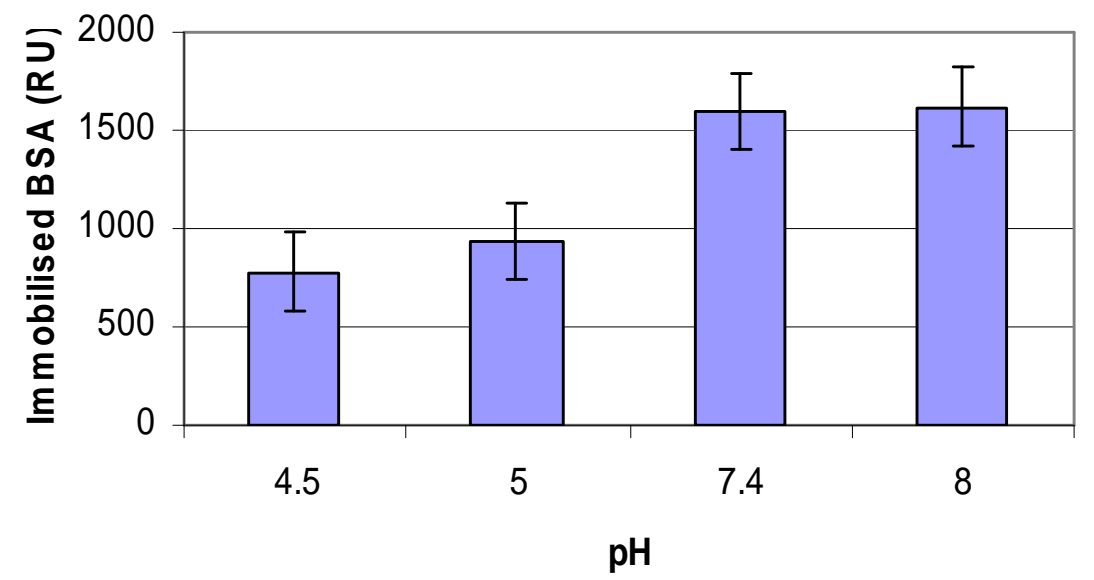

Figure 3. Influence of buffer $\mathrm{pH}$ on the immobilisation of BSA $\left(100 \mu \mathrm{g} \mathrm{mL}^{-1}\right)$ onto polymer-coated surfaces. 


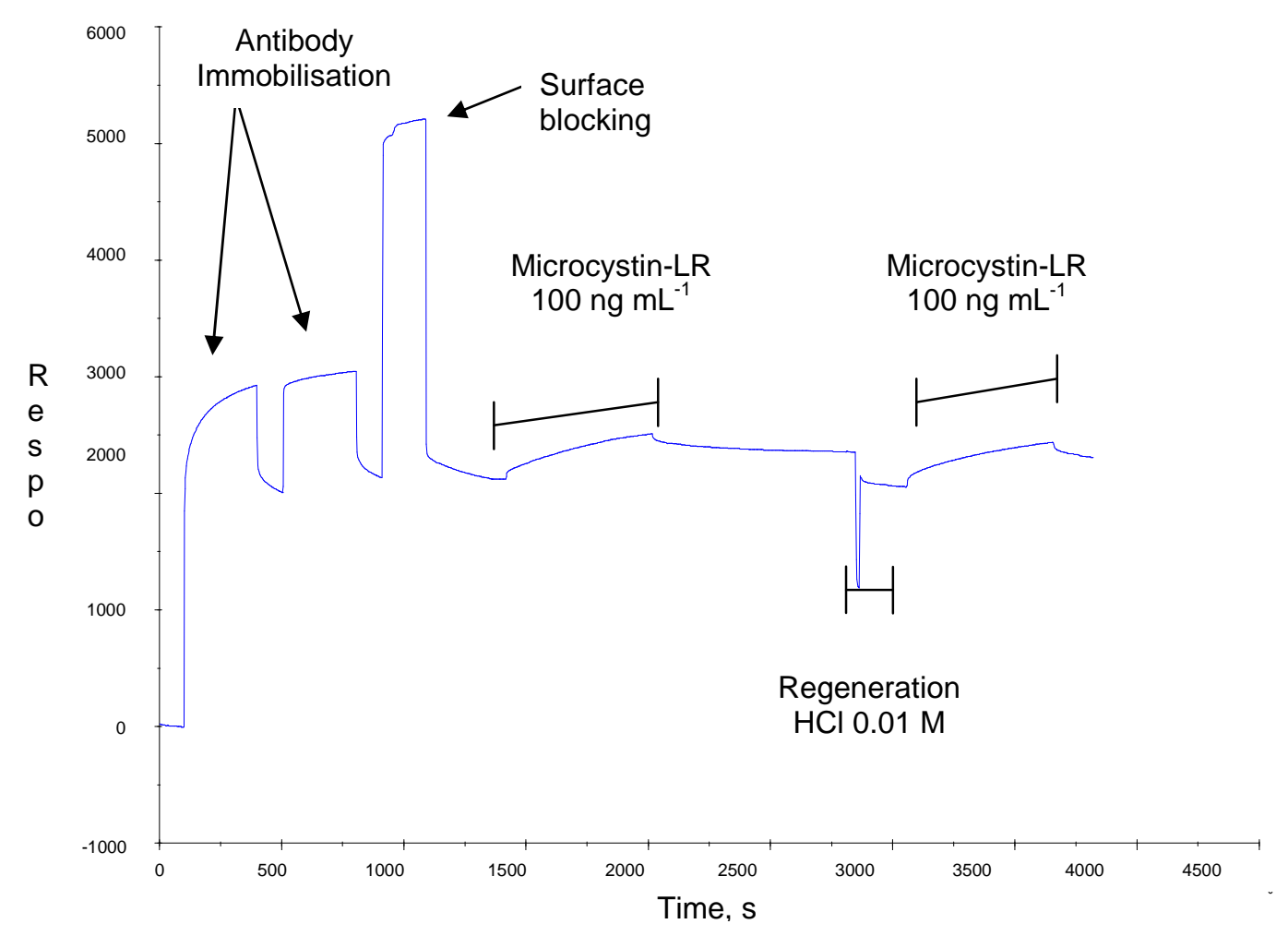

Figure 4. A Biacore sensogram showing microcystin-LR immunodetection. The first two injections correspond to the antibody (polyclonal anti-microcystin-LR $\mathrm{Ab}$ ) immobilisation; blocking of unreacted binding sites with 1 M ETA, $\mathrm{pH} 8.5$ follows. The binding of $100 \mathrm{ng} \mathrm{mL}^{-1}$ microcystin-LR then occurs by a $50 \mu \mathrm{L}$ injection in 0.01

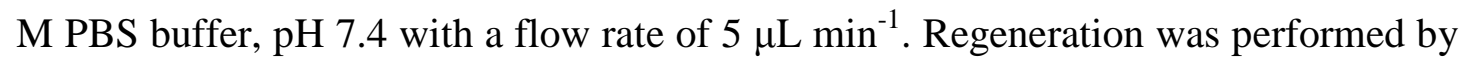
injecting $10 \mathrm{mM} \mathrm{HCl}$ for $10 \mathrm{sec}$. At the end, a rebinding of microcystin-LR to regenerated $\mathrm{Ab}$ showing the same performance as in the first cycle is reported. 


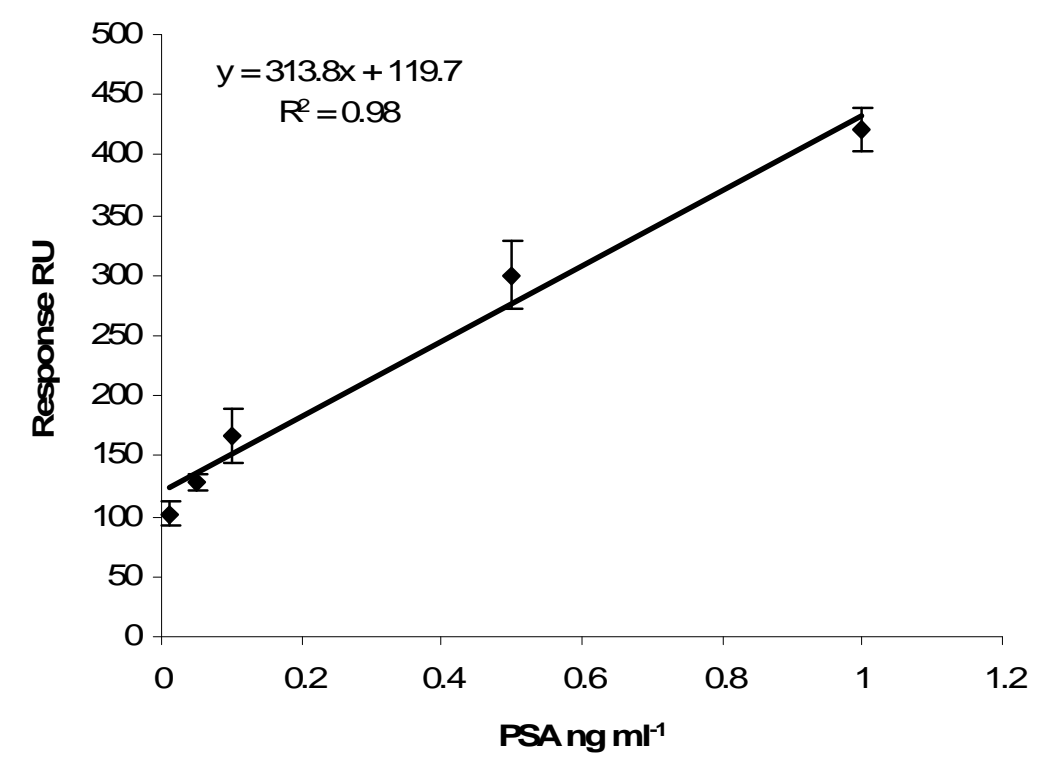

Figure 5. Calibration curve of PSA obtained using monoclonal anti-PSA Ab immobilised on the polymer-coated surface.

Table 1: PSA binding in the concentration range of $0.01-1.0 \mathrm{ng} \mathrm{mL}^{-1}$ to monoclonal anti-PSA Ab immobilised onto the polymer-coated surface. The non-specific binding to a reference channel blocked with BSA and ethanolamine is reported in the third column. Anti-PSA immobilised was $1976 \pm 9.2 \% \mathrm{RU}$.

\begin{tabular}{cccc}
\hline $\begin{array}{c}\text { PSA } \\
\left(\mathrm{ng} \mathrm{mL}^{-1}\right)\end{array}$ & $\begin{array}{c}* \text { PSA binding to } \\
\text { monoclonal } \mathrm{Ab}(\mathrm{RU})\end{array}$ & $\begin{array}{c}* \text { PSA binding to } \\
\text { reference channel (RU) }\end{array}$ & $\begin{array}{c}\text { Net binding signal } \\
(\mathrm{RU})\end{array}$ \\
\hline 0.01 & $112.4 \pm 8.8 \%$ & $10.3 \pm 10.6 \%$ & 102.1 \\
0.05 & $155.5 \pm 4.5 \%$ & $26.4 \pm 15.5 \%$ & 129.1 \\
0.1 & $232.4 \pm 9.9 \%$ & $65.1 \pm 10.4 \%$ & 167.3 \\
0.5 & $440.4 \pm 6.7 \%$ & $140.0 \pm 17.9 \%$ & 300.4 \\
1 & $617.6 \pm 2.9 \%$ & $197.1 \pm 9.8 \%$ & 420.5 \\
\hline
\end{tabular}

* Standard deviation was calculated from a set of 3 experiments. 
Table 2. Immobilisation of enzymes and BSA on polymer-coated chip, CM3 and CM5 sensor chips. The results were obtained using Biacore 3000.

\begin{tabular}{ccccc}
\hline Protein & pI & $\begin{array}{c}\text { Polymer coated } \\
\text { chip (RU) }\end{array}$ & CM3 (RU) & CM5 (RU) \\
\hline Pepsin & 1 & $1165 \pm 0.4 \%$ & $56 \pm 21.4 \%$ & $39 \pm 23.1 \%$ \\
BSA & $4.5-5.5$ & $1596 \pm 7.1 \%$ & $1232 \pm 18.6 \%$ & $12030 \pm$ \\
Carbonic & & & & $6.9 \%$ \\
Anhydrase & 6.5 & $1780 \pm 3.2 \%$ & $4450 \pm 0.7 \%$ & $6845 \pm$ \\
Trypsin & 10 & $1716 \pm 2.3 \%$ & $499 \pm 12.2 \%$ & $4754 \pm$ \\
& & & & $7.4 \%$ \\
\hline
\end{tabular}

